\title{
Exploring Self-Leadership across Eastern and Western Cultures
}

\author{
Jessie $\mathrm{Ho}^{1}$, Paul L. Nesbit ${ }^{2}$ \\ ${ }^{1}$ Hong Kong Community College, Hong Kong Polytechnic University, Kowloon, Hong Kong, China; ${ }^{2}$ Macquarie Graduate School of \\ Management, Macquarie University, Sydney, Australia. \\ Email: ccjessie@hkcc-polyu.edu.hk
}

Received June $26^{\text {th }}, 2013$; revised July $28^{\text {th }}, 2013$; accepted September $3^{\text {rd }}, 2013$

Copyright (C) 2013 Jessie Ho, Paul L. Nesbit. This is an open access article distributed under the Creative Commons Attribution License, which permits unrestricted use, distribution, and reproduction in any medium, provided the original work is properly cited.

\begin{abstract}
The purpose of this study was to examine how culture influences the use of self-leadership strategies among Hong Kong and Australian students. Results revealed that significant cultural differences were found for some dimensions of self-leadership strategies. Chinese students reported greater use of self-reward, relation-based natural reward, individual-oriented and social-oriented evaluation of beliefs and assumption, whereas Australian students reported greater use of self-goal setting, and self-cueing. However, no cultural differences were found for the use of self-punishment, positive self-talk, visualizing successful performance as well as task-based natural rewards. Implications and future research are also discussed.
\end{abstract}

Keywords: Self-Leadership; Cross-Cultural Comparison; Independent-Interdependent Self-Construals; Individualistic/Collectivistic Cultures; Promotion and Prevention Regulatory Focus

\section{Introduction}

Over the past two decades, multi-national organizations have restructured, and moved toward decentralized, organic-type organizational structures [1] in response to the rapid changes in the business environment. People with high levels of capacity and skills in self-direction and self-influence should respond more successfully and effectively to the dynamic changes of organization structures and environments [2]. Thus, self-leadership which is defined as "a self-influence process through which people achieve the self-direction and self-motivation necessary to perform" [3], has become an important concept in management research.

Self-leadership strategies are typically classified into three categories, namely behavior-focused strategies, natural reward strategies, and cognitive or thought pattern strategies [4]. Behavior-focused self-leadership involves using action-oriented strategies to accomplish tasks that are difficult or are neither enjoyable nor motivating. Sims and Manz [5] identified various behaviorfocused self-leadership strategies, including self-observation, self-goal setting, self-reward, self-punishment, and self-cueing strategies. Natural reward strategies are designed to enhance intrinsic motivation for better per- formances by focusing one's attention on the pleasant aspects of a given job and by engaging in job- or taskredesign to build in more enjoyable work activities [4,5]. Constructive thought strategies involve visualizing successful performance, engaging in positive self-talk, and examining individual beliefs and assumptions to align cognitions with desired behavior [6]. Research on the use of self-leadership strategies has found it to be effective at enhancing performance in clinical, athletic, and educational settings [7], and in employment contexts [8].

With the increasing numbers of multinational corporations in the global economy and increased interdependencies among nations, employees are increasingly required to work with others from diverse nationalities and cultural backgrounds. Consequently, management scholars have become more interested in understanding how culture influences behavior in organizational settings. Thus, given the growing importance of self-leadership in contemporary organizations operating in an increasingly global and interdependent environment, there is a need to explore the applicability of self-leadership theory across cultures $[3,8,9]$. Most researches on self-leadership have been conducted in the United States, which represent a relatively individualistic, western culture. While it has been argued that self-leadership behavior is a generally uni- 
versal concept [8], there is need to empirically explore whether self-leadership strategies may be applied differently across cultures. For example, Alves et al. [8] conceptually explored the cross-cultural application of selfleadership using Hofstede's [10] culture framework and proposed that "high power distance was likely to contribute to a more restricted and contingent form of selfleadership where the extent of self-influence practiced that was independent of cultural expectations and norms is more limited."

Georgianna [11] also studied the influence of culture on young adults' use of self-leadership strategies. This study provided evidence that the US respondents expressed higher levels of self-leadership than the Chinese respondents. However, each self-leadership strategy was measured by only one item and so may not adequately capture the theoretical conceptualization of self-leadership proposed by self-leadership theorists [4,11]. In order to advance cross-cultural research on self-leadership, research utilizing a more reliable self-leadership scale is needed.

The purpose of this study is to examine how culture influences individuals' use of self-leadership strategies among the Chinese and Australian respondents, using a recently developed self-leadership scale [12], which has been found to be valid and reliable for use in both Eastern and Western cultures [13]. We begin with a discussion on how differences in self-construal between Eastern and Western cultures shapes peoples' self-regulatory orientation, which in turn result in differences in the way people regulate their behaviors toward goals accomplishment across cultures. We then develop specific hypotheses for our research and outline a study that explores differences between Eastern and Western participants in the practice of self-leadership strategies.

\section{Overview}

\subsection{Literature Review}

Considerable research in cultural psychology has identified two types of self-construal: the independent and the interdependent self-construal [14]. Independent self-construal represents a view of oneself as an independent, self-reliant, autonomous individual who is separate from the social context. The interdependent self-construal, on the other hand, involves viewing oneself as "part of an encompassing social relationship" [14]. According to Markus and Kitayama [14], people in Western and Eastern cultures differ in their views about the self. In Western cultures, such as North America and Australia, an independent self-construal predominates and people are motivated to become independent from others and to pursue the expression of one's unique configuration of needs, rights, and capacities. In Eastern cultures, such as
China and Japan, an interdependent self-construal predominates, people tend to suppress and restrain inner attributes such as desire, personal goals and private emotions to fit in with significant others, and to meet social obligations as part of social networks.

It has also been noted that these two different selfconstrual types are also reflected in the way people orient towards goal accomplishment and the way they regulate their behavior [15]. According to regulatory focus theory [15], there are two fundamental self-regulatory orientations: promotion and prevention. Promotion regulatory focus involves peoples' desire for advancement, growth, and accomplishment, whereas the prevention regulatory focus involves peoples' concern for safety, obligation and responsibility [16].

Lee, Aaker and Gardner [17] argued that the primary goal of the independent self-construal is seen as developing one's unique potential through the pursuit of success and accomplishments. Thus, the goals of those with independent self-construal are viewed as more consistent with a promotion focus. In contrast, the primary goal of those with interdependent self-construal is to maintain harmony and connections with others, and to fulfill their social obligations [14]. Thus, people with a dominant interdependent self-construal are inclined to avoid social disapproval or failures that may disrupt their commitment of enhancing social relations, which is more consistent with a prevention focus. Lee, Aaker and Gardner [17] experimental studies provided evidence that individuals with a dominant independent self-construal perceived promotion-framed scenarios to be more important than prevention-framed scenarios. In contrast, those with a dominant interdependent self-construal perceived prevention-focused scenarios to be more important than promotion focused scenarios.

These differences in self-construal and regulatory focus have potential to result in differences in the practice of self-leadership strategies. Individualists (who are known to hold a predominant independent self-construal) may, for example, use self-leadership strategies that support the regulation of their cognitions and behaviors toward positive outcomes such as advancement and achievement. We expect that such individualists are more likely than collectivists to initiate the setting of challenging goals, apply self-rewards imposed for energizing the effort towards goal achievement, and construct certain concrete environmental cues (e.g. notes, motivational posters) used for shaping constructive behaviors. The application of these three self-leadership strategies may enhance the individualists' perceived control and selfefficacy in attaining their desired outcomes.

In contrast, collectivists (who are known to hold a predominant interdependent self-construal) strive to harmoniously fit in with others and to live up the expectations 
of significant others. Since collectivists place more emphasis on avoiding negative outcomes [14], they are more likely to exhibit prevention focus behaviors in their desire to avoid failure and mistakes that may jeopardize their goals of maintaining social harmony. Thus collectivists are expected to use self-leadership strategies in order to regulate their cognitions and behaviors away from negative outcomes.

Research on self-regulatory focus has provided evidence that promotion-focus individuals are more persistent than prevention-focus individuals to attain success at difficult problem solving tasks [18]. Crowe and Higgins [18] found that participants in promotion-focus framing conditions persisted longer in solving more anagrams than those in the prevention-focus framing conditions. It was argued that individuals under prevention-focus framing conditions tend to quit difficult problem tasks earlier to avoid prolonging engagement with making mistakes. Given that promotion-focused individualists appear to place more value on the pursuit of personal success and accomplishment, we expect that Australian students, who represent individualists in this study, are more likely to set personal goals, construct environmental cues and apply self-reward to guide themselves than Hong Kong Chinese students who represent collectivists.

H1: Australian students are more likely to apply selfgoal setting strategy, self-reward strategy and self-cueing strategy than Hong Kong students.

It has been suggested that the adoption of a promotion regulatory focus among individualists involves sensitivity to the presence or absence of positive outcomes [15]. Such sensitivity may heighten individualists' attention on the positive side of their accomplishments. Previous studies found that individualists are more likely to attend to positive information than to negative information regarding themselves $[19,20]$. For example, Western individuals may uncritically accept positive feedback while critically evaluating negative feedback [21]. Heine [22] also suggested that individualists are more likely to engage in self-deceptive enhancement so as to boost their self-image. Since promotion-focused individualists are eager to see themselves in a positive manner, we propose that Australian students, who represent individualists, are more likely to lead themselves through the strategy of visualizing successful performance and positive self-talk. Positive self-talk is an optimistic internal dialogue people use to encourage themselves for goal achievement $[4,23]$. Visualizing successful performance involves imagining the successful completion of a task or activity [4]. These two strategies are mental techniques which are expected to help individualists to maintain a self-reliant, and competent self-view.

In contrast to individualists who are sensitive to the presence or absence of positive outcomes, collectivists, driven by the need to feel secure and to avoid getting social disapproval, tend to focus on the negative information about the self [24]. For example, research has found that Japanese are more self-critical than are North Americans [16]. Lee, Aaker and Gardner [17] stressed that "on the basis of the identification of what is lacking in the self, steps are taken to improve on these deficits to become a better, more unified part of the relevant social unit, a tendency that appears to grow over time as nurtured by socialization processes."

Therefore, the strategies of positive self-talk and visualizing successful performance are less relevant for collectivists' goals of improving interpersonal relations. Instead, self-punishment strategy, which involves self-criticism and guilt associated with one's unsatisfactory performance, would be more relevant for the collectivists. Self-punishment supports correction of task focused behavior, which is consistent with a prevention regulatory focus and the collectivist need for social acceptance. However, self-punishment strategy contributes little to individualists' needs of maintaining competent, positive self-views. Thus, we suggest different use of self-talk, visualization, and self-punishment strategies between the Hong Kong Chinese and Australian students.

H2: Australian students are more likely to apply visualizing successful performance and positive selftalk strategy than the Chinese students.

H3: Chinese students are more likely to apply selfpunishment strategy than the Australian students.

Self-leadership's conceptualization of natural rewards is based primarily on the intrinsic motivation literature, particularly Deci and Ryan's [25] self-determination theory. Feelings of autonomy and competence are a central focus in the task-based natural rewards strategy component of self-leadership [4]. This strategy involves building more pleasant and enjoyable features into a given activity and assumes that once activities and task can be restructured or perceived in ways that lead to increased feelings of competence and self-determination, the enjoyment of the task will be enhanced, resulting in higher task performance [5]. However, while the enjoyment of the task attached to the values of autonomy and self-determination may hold true for those from Western cultures emphasizing independence, it may be less relevant for people from Eastern cultures with a strong need of relatedness. Iyengar and DeVoe [26] argued that in cultures that foster social interdependence, collectivists might prefer to submit to choices expressed by others if the situation enables them to fulfill the superordinate cultural goal of belongingness. For example, Iyenger and Lepper [27] found that the intrinsic motivation and performance of Asian American children was highest, not in contexts offering personal choice, but in those in which choices were determined for them by valued in-group 
members or trusted authority figure (e.g. their mothers). Given that the feelings of maintaining in-group harmony and belongingness rather than the feelings of self-determination and competence may act as a major source of task enjoyment in collectivistic culture [27], we expect that relation-based natural reward strategy which involves getting work enjoyment through maintaining connections with others is more relevant for collectivists than for individualists. Thus we argue that Australian students with a dominant independent self view may use task-based natural reward strategy more often than do the Hong Kong Chinese students, whereas the Chinese respondents with a dominant interdependent self may apply relation-based natural reward strategy more frequently than do the Australian respondents.

H4: Australian students are more likely to apply taskbased natural rewards than the Chinese students.

H5: Chinese students are more likely to apply relationbased natural rewards than the Australian students.

While cultural value influences the way people get enjoyment from their jobs, it also shapes individuals' ways of controlling their own thought and beliefs inherent in goal achievement. According to Kim and Markus [28], people from individualistic cultures are encouraged to search for their own dreams and freedom beyond the constraints imposed by rules, norms, and others' expectation. Accordingly, individualists may seek to regulate themselves for personal success by reference to their own internal repertoire of thoughts, feelings, and actions, rather than by reference to the standards and opinions of others or social groups [16]. In contrast, people from collectivistic culture are motivated to find a way to fit in with relevant others, to fulfill obligation in order to become part of interdependent interpersonal relationships [14]. Given that the goal-striving behaviors of individualists are more self-oriented than collectivists, the strategy of social-oriented evaluation of beliefs and assumption with a strong focus on improving social relations is less relevant. In contrast, collectivists are more likely to use social-oriented evaluations of beliefs assumption strategy because it helps them to adjust their own viewpoints to avoid conflicts with those of their in-group [12].

In addition, the self-leadership strategy of examining one's individual-oriented beliefs and assumptions is expected to be more suitable for individualists than for collectivists. Evaluating beliefs and assumptions aims to help one recognize one's dysfunctional thinking and destructive beliefs, learn to challenge them, and replace them with more constructive thoughts. Using this strategy may help individualists to enhance their personal success by reflecting on their own thinking processes relative to their goals. However, individual-oriented belief and assumption strategy may be less relevant for collectivists who place heavy emphasis on improving social relations and maintaining one's respected place within a group. On this basis we expect to see the following differences in the nature of evaluation of beliefs and assumptions among the Australian and Hong Kong Chinese students.

H6: Chinese students are more likely to apply socialoriented evaluation of beliefs and assumptions than the Australian students.

H7: Australian students are more likely to apply individual-oriented evaluation of beliefs and assumptions than the Chinese students.

\section{Method}

\subsection{Participants}

Participants were from Hong Kong and Australia and represented two diverse cultures. The collectivist cultural value is assumed to be maintained among these Chinese participants from Hong Kong, especially given the strong influence of the Chinese social influences, such as exposure to Chinese mainland influences and by the fact that the Hong Kong students' education was mostly conducted in Cantonese. Hofstede [10] and Oyserman, Coon and Kemmelmeir [29] have found that Australia has emerged as one of the most individualistic societies in the world.

Chinese sample. Responses were collected from 395 full-time Chinese students (64\% female; $36 \%$ male) undertaking business classes at a community college in Hong Kong. Ages ranged from 18 to 29 (Mean $=19.9$, S.D. $=1.16$ ). The questionnaires were completed anonymously and participation was voluntary without compensation.

Australian sample. The sample was made up of 241 Australian full-time students who were born and had lived all their lives in Australia (69\% female; $31 \%$ male). All respondents were recruited from two public universities located in Sydney. Ages ranged from 17 to 50 (Mean $=20.4$; S.D. $=4.55$ ). All students were undertaking psychology classes and received course credit for their participation. In order to maximize the possible differentiation between the two cultural groups, overseas born students were excluded from the respondent sample.

\subsection{Measures}

Self-leadership was measured using the modified Selfleadership Questionnaire (MSLQ) developed by Ho and Nesbit [12]. Ho, Nesbit, Jepsen and Demirian [13] have provided evidence that the MSLQ is equivalent across the Chinese and Western cultures. Thus, the MLSQ is a reliable measure for this study to make valid cross-cultural comparisons. For detailed discussion regarding the 
statistical procedures of testing measurement invariance, please refer to the study conducted by Ho, Nesbit, Jepsen and Demirian [13]. The MSLQ consists of 38 items describing various behaviors associated with self-leadership and participants use a 5-point Likert-type scale $(1=$ not all accurate; 2 = little accurate; $3=$ somewhat accurate; $4=$ mostly accurate; $5=$ completely accurate) to indicate how accurately each behavior describes them. The 10 subscales include Visualizing Successful Performance (2 items); Self-goal Setting (4 items); Self-talk (3 items); Self-reward (3 items); Self-punishment (4 items); Taskbased Natural Reward (4 items); Relation-based Natural Reward (4 items); Individual-oriented Evaluation of Beliefs and Assumptions (5 items); Social-oriented Evaluation of Beliefs and Assumptions (3 items); Self-cueing (2 items). Sample items include "I use my imagination to picture myself performing well on important tasks," "I consciously have goals in mind for my work efforts," "I think that the enjoyment gained from work is more important than external rewards," and "When I differ from others' opinions, I try to modify my thinking to avoid conflicts so as to maintain harmony." See Ho and Nesbit's [12] validation research for the complete questionnaire.

\section{Results}

\subsection{Data Analysis Procedure}

In the present study, following the procedure outlined by Byrne [30], we used the analysis of latent-mean differences through multi-group confirmatory factor analysis to test for the seven hypotheses stated above. It has been suggested latent-mean differences are more valid than the analysis of variance (ANOVA) or $t$-tests [31], as the method accommodates varying degrees of partial measurement invariance (see Reise, Widaman and Pugh [32]), which was the case for the MSLQ reported in Ho et al. [13]. Latent construct means were compared by allowing eight intercepts (found to be not equivalent across groups in this study) to vary freely while constraining other intercepts and all factor loadings, to be identical across groups $[31,33]$. As part of this procedure, it was necessary to allow latent-variable means (e.g. average mean score of self-goal setting factor) to be freely estimated for the Australian group but to be constrained to zero for the Chinese group, which served as a "reference group". Selection of which cultural group would serve as the reference group is purely arbitrary [32]. Significant positive mean differences would indicate that the Australian group reported higher ratings on a given measure. In determining significant differences, the critical ratio with values greater than \pm 1.96 indicated statistical significance $(p \leq 0.05 ;[34])$.

\subsection{Test of Hypotheses}

As shown in Table 1, compared with the Chinese respondents, Australian respondents reported significantly higher use of self-goal setting $\left(\operatorname{mean}_{\text {diff }}=0.162, p<0.05\right)$, self-cueing $\left(\operatorname{mean}_{\text {diff }}=0.392, p<0.001\right)$. This was consistent with H1. However, Australian respondents reported less use of self-reward strategy $\left(\operatorname{mean}_{\text {diff }}=-0.266\right.$, $p<0.001)$ than did Chinese respondents which was in the opposite direction to the prediction of H1. Therefore, H1 was only partially supported. There were no significant cultural differences in visualizing successful performance $\left(\operatorname{mean}_{\mathrm{diff}}=-0.076, p>0.05\right)$, positive self-talk $\left(\right.$ mean $\left._{\text {diff }}=0.080, p>0.05\right)$, self-punishment $\left(\right.$ mean $_{\text {diff }}=$ $0.002, p>0.05)$ and task-based natural reward (mean diff $=-0.106, p>0.05$ ). Thus H2, H3, and H4 were not supported.

As predicted, Chinese respondents reported significantly higher use of relationship-based natural reward $\left(\right.$ mean $\left._{\text {diff }}=-0.339, p<0.001\right)$ and social-oriented evaluation of beliefs and assumptions $\left(\right.$ mean $_{\text {diff }}=-0.372, p<$ 0.001) than Australian respondents. Thus, H5 and H7 were supported. Moreover, contrary to the prediction of H6, Chinese respondents reported using individual-oriented evaluation of beliefs and assumptions to a greater extent than did Australian respondents $\left(\operatorname{mean}_{\text {diff }}=-0.135\right.$, $p<0.05)$. Hence, H6 was not supported in this study.

\section{Discussion}

The purpose of this study was to examine whether culture influences the individuals' use of self-leadership strategies. In the present study, significant cultural differences were found for some dimensions of self-leadership strategies among the Chinese and Australian respondents. As predicted, Chinese students utilized the relation-based natural reward and social-oriented evaluation of beliefs and assumption strategy more frequently than Australian students. This finding suggested that these two strategies, which are associated with some social/relation-based features, are more suitable for Chinese who have interdependent self-construal and are more motivated to maintain in-group harmony and to act in accordance with the anticipated expectations of others and social norms. On the other hand, the Australian students, who have independent self-construal, used self-goal setting, and self-cueing strategy more often than did the Chinese students. These findings are consistent with hypotheses developed from regulatory focus theory [15] and the theory of independent-interdependent self-construals [14]. Specifically, Australian respondents with independent selves tend to be more promotion-focused. Hence, they are more proactive in setting their own goals and environmental cues so as to enhance their persistence in achieving personal success. 
Table 1. Results for latent mean difference tests

\begin{tabular}{|c|c|c|c|c|}
\hline Measure & Mean difference & Standard Error & Critical Ratio & $P$ \\
\hline Self-goal setting & 0.162 & 0.067 & 2.439 & 0.015 \\
\hline Self-reward & -0.266 & 0.077 & -3.458 & $<0.001$ \\
\hline Self-Cueing & 0.392 & 0.086 & 4.544 & $<0.001$ \\
\hline Visualizing successful performance & -0.076 & 0.083 & -0.910 & $>0.05$ \\
\hline Positive self-talk & 0.080 & 0.091 & 0.882 & $>0.05$ \\
\hline Self-punishment & 0.002 & 0.054 & 0.035 & $>0.05$ \\
\hline Task-based natural reward & -0.106 & 0.071 & -1.490 & $>0.05$ \\
\hline Relation-based natural reward & -0.339 & 0.066 & -5.123 & $<0.001$ \\
\hline Individual-oriented evaluation of beliefs and assumption & -0.135 & 0.066 & -2.059 & $<0.05$ \\
\hline Social-oriented evaluation of beliefs and assumption & -0.372 & 0.055 & -6.722 & $<0.001$ \\
\hline
\end{tabular}

It is interesting that, contrary to predictions, the Chinese students utilized the strategies of self-reward and individual-oriented evaluation of beliefs and assumption more often than the Australian students. In addition, there were no significant differences between the Chinese and Australian students in terms of the mean scores measuring visualizing successful performance, positive self-talk, self-punishment and task-based natural rewards.

Given that students from Hong Kong and Australian were the respondents in this study, then self-leadership strategies would be most likely referenced in relation to how students manage themselves in performing at University. Thus an explanation for these mixed findings may arise from different cultural values for the achievement of academic goals. According to Bond [35], for Chinese students "social skills, athletic ability or personal fulfillment are secondary to doing well in school $\cdots$ since academic achievement is still a major escalator to higher position, parents exert massive pressure on their children to do well in school". Additionally, education research has found that Asian students possess higher achievement motivation than Western students because Asians believe all performance is linked to an internal and controllable source-effort, whereas Westerners believe more in fixed ability [36,37]. This belief influences Asian parents to place higher academic expectations on their children [38]. Reglin and Adams [39] found that even among Asian students brought up in the American culture, these children are more influenced by their parents' desire for success than are their non-Asian counterparts. Thus, Asian students' desire to meet their parents' academic expectations, coupled with their belief in learning through effort rather than being a fixed ability, may translate into higher level of self-control effort striving for academic success.

In addition, the Confucian tradition in teaching is still a major source of influence on child rearing practices in
Hong Kong [40]. Confucius's conception of learning is a process of "studying extensively, inquiring carefully, pondering thoroughly, sifting clearly, and practicing earnestly" [41]. According to Tang and Biggs [42], "success comes to those who apply themselves to their allotted tasks unremittingly; with diligence, you can grind an iron bar into a needle, as a Chinese proverb puts it." Memorization is viewed as an important way to get familiar with learning content. In order to ensure accurate recall of already understood information, Hong Kong students tend to practice repetitive learning [43], which are unpleasant and boring. To deal with the unattractive but necessary tasks of memorization, Hong Kong Chinese students may take more initiative to apply the strategies of self-reward and individual-oriented evaluation of beliefs. That is, these Chinese students may tend to reward themselves with things and activities they enjoy when they accomplish their academic goals. Also, to reduce their intense stress they face at school, they may be more inclined to identify their dysfunctional beliefs and replace them with more rational thoughts.

Thus an explanation for the unexpected findings in this study is that Chinese students possess a high need to approach academic success because of the Chinese value of educational achievement [42] and thus such tendencies may propel Chinese students to become more promotion-focused. Similar to the Australian students, they tend to see themselves in a positive manner so as to maintain a self-reliant, competent self-view. In so doing, they may downplay the role of self-criticism (self-punishment strategy) so as to minimize its negative impact on selfconfidence and practice the self-motivated strategies of visualizing successful performance, positive self-talk and task-based natural rewards as often as did the individualists (Australian students). Such tendencies result in the insignificant differences across cultures in the use of these four strategies. 
However, despite the fact that Chinese exhibit promotion focus in their use of many self-leadership strategies, they were less likely to apply self-goal setting strategy and self-cueing strategy than the Australian students. These behaviors may be explained by the collectivistic self-construal of Chinese students who seek to meet standards set by significant others, such as teachers and parents. Australian students, on the other hand, have individualistic self-construal and so are more inclined to set their own goals. As their teachers play little role in influencing their goal-setting process, the Australian students should apply more self-cueing strategies to help them behave in desirable ways. For example, the Australian students may create a list of some important tasks they should accomplish for building up their career such as attending career talk, or searching for an internship jobs based on their career preference. While these explanations are tentative, they suggest that in addition to the cultural differences in self-construal and regulatory focus, the cultural values in relation to types of individual goals (e.g. academic goal) may play an important role in shaping the differences and similarities in the use of selfleadership strategies between the Chinese and Australian students.

Given the current trend of globalization, it is increasingly likely that managers working in multinational corporations are required to manage their subordinates from different cultures. Furthermore, as mentioned earlier, over the past two decades, multi-national organizations have restructured, and moved toward decentralized, organic-type organizational structures [1] in response to the rapid changes in business markets. People with high level of self-leadership skills could respond more effectively to the dynamic changes of organization structures and environments. Consequently, global managers may improve their managerial effectiveness by understanding how their subordinates with different cultural backgrounds lead themselves to reach their goals. This study provides the global managers some insights in respect of the cross-cultural similarities and differences in the use of self-leadership between Eastern and Western populations. Especially, significant cultural differences found in this study may suggest that Chinese employees are less likely to use self-goal setting, and self-cueing, whereas Australian employees are less likely to use relation-based natural reward and social-oriented evaluation of beliefs and assumption. Global managers could lead their Chinese subordinates to set their own challenging goals, and construct certain environmental cues used for shaping desirable behaviors. Furthermore, those subordinates from individualistic cultures are encouraged to improve their performance in team projects by using those relation-based self-leadership strategies so as to build better work relationships with their co-workers.

\section{Limitation and Future Research}

The present study is not without inherent limitation. The use of a student sample may limit the generalizability of the results, despite the cultural appropriateness of the sample used. Future researchers may consider using other population samples, such as work employees from both Eastern and Western culture. Especially in Chinese organizational setting, paternalistic leadership deeply rooted in Confucian tradition is the prevalent leadership style in which the leaders have high level of power centralization and control over subordinates and demand unquestionable obedience from subordinates [44]. Because of the Chinese tradition of role compliance, Chinese employees are more likely to depend on the guidance and authority of their supervisors. Thus, compared with the Western workers, Chinese employees may take less initiative to practice self-leadership strategies, especially those individual-centered strategies helping selfleaders to enhance their perception of autonomy, and competent self-view such as task-based natural rewards, individual-oriented evaluation of beliefs and assumptions, visualizing successful performance, and positive self-talk. Furthermore, such research on which self-leadership strategies are most useful for Chinese and Australian employees to enhance their self-efficacy, job satisfaction and performance in job settings has implications for crosscultural leadership and employee development. Thus, more future research is needed to investigate the relative importance of different self-leadership strategies in predicting work outcomes across cultures.

It would also be of interest to examine whether the findings presented here could be applied to other collectivistic cultures such as Latin American where social ties are stressed [45] without a strong emphasis on academic achievement. Cross-cultural differences in the use of selfleadership strategies are more likely to happen between collectivists from Brazil or Columbia and individualists from USA or Australia.

Our study assumed that the Hong Kong subjects were collectivists, whereas the Australian subjects were classified as individualists. Without measuring the cultural differences of these two samples in terms of the individualism-collectivism orientation [46], it is possible that these young Hong Kong students may be open to greater influence from Western culture and be more individualistic in their values, like the Australian sample. However, we are not aware of any empirical research arguing for a convergence of cultural values among young Hong Kong Chinese to Western Individualism. While it is unlikely that these two samples are similar in terms of their cultural value orientation, we nevertheless, suggest that future studies utilize specific measures of individualism/ collectivism in their research.

In conclusion, this study revealed some mixed results. 
Chinese students reported greater use of self-reward, relation-based natural reward, individual-oriented and social-oriented evaluation of beliefs and assumption, whereas Australian students reported greater use of selfgoal setting, and self-cueing. However, no cultural differences were found for self-punishment, positive selftalk, visualizing successful performance as well as taskbased natural rewards. These findings may serve as a road map for educators to understand how their students from collectivist/individualistic culture lead themselves to reach their goals. More future research is needed for studying how students in various cultures practice selfleadership strategies and how these in turn influence their learning and academic achievement.

\section{REFERENCES}

[1] J. A. Conger and R. M. Kanungo, "The Empowerment Process: Integrating Theory and Practice," The Academy of Management Review, Vol. 13, No. 3, 1988, pp. 471482.

[2] M. D. Ensley, K. M. Hmieleski and C. L. Pearce, "The Importance of Vertical and Shared Leadership within New Venture Top Management Teams: Implications for the Performance of Startups," The Leadership Quarterly, Vol. 17, No. 3, 2006, pp. 217-231. http://dx.doi.org/10.1016/j.leaqua.2006.02.002

[3] C. P. Neck and J. D. Houghton, "Two Decades of SelfLeadership Theory and Research: Past Developments, Present Trends, and Future Possibilities," Journal of Managerial Psychology, Vol. 21, No. 4, 2006, pp. 270295. http://dx.doi.org/10.1108/02683940610663097

[4] C. C. Manz and C. P. Neck, "Mastering Self-Leadership: Empowering Yourself for Personal Excellence," 3rd Edition, Pearson Prentice Hall, Upper Saddle River, 2004.

[5] H. P. Jr. Sims and C. C. Manz, "Company of Heroes: Unleashing the Power of Self-Leadership," Wiley, New York, 1996.

[6] C. P. Neck, G. Stewart and C. C. Manz, "Thought SelfLeadership as a Framework for Enhancing the Performance of Performance Appraisers," Journal of Applied Behavioral Science, Vol. 31, 1995, pp. 278-302. http://dx.doi.org/10.1177/0021886395313004

[7] C. P. Neck and C. C. Manz, "Thought Self-Leadership: The Impact of Self-Talk and Mental Imagery on Performance," Journal of Organizational Behavior, Vol. 12, 1992, pp. 681-699.

http://dx.doi.org/10.1002/job.4030130705

[8] J. C. Alves, K. J. Lovelace, C. C. Manz, F. Matsupura, D. Toyasaki and K. Ke, "A Cross-Cultural Perspective of Self-Leadership," Journal of Managerial Psychology, Vol. 21, No. 4, 2006, pp. 338-359. http://dx.doi.org/10.1108/02683940610663123

[9] M. J. Neubert and J. C. Wu, "An Investigation of the Generalizability of the Houghton and Neck Revised SelfLeadership Questionnaire to a Chinese Context," Journal of Managerial Psychology, Vol. 21, No. 4, 2006, pp. 360-

\section{3. http://dx.doi.org/10.1108/02683940610663132}

[10] G. Hofstede, “Culture's Consequences: International Differences in Work-Related Values," Sage Publications, San Francisco, 1980.

[11] S. Georgianna, "Self-Leadership: A Cross-cultural Perspective," Journal of Managerial Psychology, Vol. 22, No. 6, 2007, pp. 569-589. http://dx.doi.org/10.1108/02683940710778440

[12] J. Ho and P. L. Nesbit, "A Refinement and Extension of the Self-Leadership Scale for the Chinese Context," Journal of Managerial Psychology, Vol. 24, No. 5, 2009, pp. 450-476. http://dx.doi.org/10.1108/02683940910959771

[13] J. Ho, P. L. Nesbit, D. Jepsen and S. Demirian, "Extending Self-Leadership Research to the East: Measurement Equivalence of the Chinese and English Versions of the MSLQ," Asian Journal of Social Psychology, Vol. 15, No. 2, 2012, pp. 101-111. http://dx.doi.org/10.1111/j.1467-839X.2011.01366.x

[14] H. Markus and S. Kitayama, "Culture and the Self: Implications for Cognition, Emotion, and Motivation," Psychological Review, Vol. 98, No. 2, 1991, pp. 224-253. http://dx.doi.org/10.1037/0033-295X.98.2.224

[15] E. T. Higgins, "Beyond Pleasure and Pain," American Psychologist, Vol. 52, No. 12, 1997, pp. 1280-1300. http://dx.doi.org/10.1037/0003-066X.52.12.1280

[16] S. H. Heine, D. R. Lehman, H. R. Markus and S. Kitayama, "Is There a Universal Need for Positive Self- Regard?" Psychological Review, Vol. 106, No. 4, 1999, pp. 766-794. http://dx.doi.org/10.1037/0033-295X.106.4.766

[17] A. Y. Lee, J. L. Aaker and W. L. Gardner, "The Pleasures and Pains of Distinct Self-construal: The Role of Interdependence in Regulatory Focus," Journal of Personality and Social Psychology, Vol. 78, No. 6, 2000, pp. 11221134. http://dx.doi.org/10.1037/0022-3514.78.6.1122

[18] E. Crowe and E. T. Higgins, "Regulatory Focus and Strategic Inclinations: Promotion and Prevention in Decision Making," Organizational Behavior and Human Decision Processes, Vol. 69, No. 2, 1997, pp. 117-132. http://dx.doi.org/10.1006/obhd.1996.2675

[19] S. J. Heine, S. Kitayama, D. R. Lehman, T. Takata, E. Ide and C. Leung, "Divergent Consequences of Success and Failure in Japan and North America: An investigation of Self-Improving Motivations and Malleable Selves," Journal of Personality and Social Psychology, Vol. 81, No. 4, 2001, pp. 599-615. http://dx.doi.org/10.1037/0022-3514.81.4.599

[20] S. E. Taylor and J. D. Brown, "Illusion and Well-being: A Social Psychological Perspective on Mental Health," Psychological Bulletin, Vol. 103, No. 2, 1988, pp. 193210. http://dx.doi.org/10.1037/0033-2909.103.2.193

[21] D. Frey and D. Stahlberg, "Selection of Information after Receiving More or Less Reliable Self-threatening Information," Personality and Social Psychology Bulletin, Vol. 12, No. 4, 1986, pp. 434-441. http://dx.doi.org/10.1177/0146167286124006

[22] S. J. Heine, "Constructing Good Selves in Japan and North America," In: R. M. Sorrention, D. Cohen, J. M. Olson and M. P. Zanna, Eds., Culture and Social Behavior: The 
Tenth Ontario Symposium, Erlbaum, New York, 2005, pp. 115-143.

[23] D. D. Burns, "Feeling Good: The New Mood Therapy," William Morrow, New York, 1980.

[24] S. Heine and D. Lehman, "Culture, Self-Discrepancies, and Self-Satisfaction," Personality and Social Psychology Bulletin, Vol. 25, No. 8, 1999, pp. 915-925. http://dx.doi.org/10.1177/01461672992511001

[25] E. L. Deci and R. M. Ryan, "Intrinsic Motivation and Self-Determination in Human Behavior," Plenum Press, New York, 1985. http://dx.doi.org/10.1007/978-1-4899-2271-7

[26] S. S. Iyengar and S. E. De Voe, "Rethinking the Value of Choice: Considering Cultural Mediators of Intrinsic Motivation," In: V. Murphy-Berman and J. Berman, Eds., Nebraska Symposium on Motivation: Cross-cultural Differences in Perspectives on Self, Vol. 49, University of Nebraska Press, Lincoln, 2003, pp. 129-741.

[27] S. S. Iyengar and R. Lepper, "Rethinking the Value of Choice: A Cultural Perspective on Intrinsic Motivation," Journal of Personality and Social Psychology, Vol. 76, No. 3, 1999, pp. 349-366. http://dx.doi.org/10.1037/0022-3514.76.3.349

[28] H. Kim and H. R. Markus, "Deviance or Uniqueness, Harmony or Conformity? A Cultural Analysis," Journal of Personality and Social Psychology, Vol. 77, No. 4, 1999 , pp. 785-800.

http://dx.doi.org/10.1037/0022-3514.77.4.785

[29] D. Oyserman, H. M. Coon and M. Kemmelmeir, "Rethinking Individualism and Collectivism: Evaluation of Theoretical Assumptions and Meta-Analysis," Psychological Bulletin, Vol. 128, No. 1, 2002, pp. 3-72. http://dx.doi.org/10.1037/0033-2909.128.1.3

[30] B. M. Byrne, "Structural Equation Modeling with AMOS: Basic Concepts, Applications, and Programming," Erlbaum, New York, 2001.

[31] R. E. Ployhart and F. L. Oswald, "Applications of Mean and Covariance Structure Analysis: Integrating Correlational and Experimental Approaches," Organizational Research Methods, Vol. 7, No. 1, 2004, pp. 27-65. http://dx.doi.org/10.1177/1094428103259554

[32] S. Reise, K. Widaman and R. Pugh, "Confirmatory Factor Analysis and Item Response Theory: Two Approaches for Exploring Measurement Invariance," Psychological Bulletin, Vol. 114, No. 3, 1993, pp. 552-566. http://dx.doi.org/10.1037/0033-2909.114.3.552

[33] J. B. Steenkamp and H. Baumgartner, "Assessing Measurement Invariance in Cross-National Research," Journal of Consumer Research, Vol. 25, No. 1, 1998, pp. 78-90. http://dx.doi.org/10.1086/209528

[34] J. L. Arbuckle and W. Wothke, "Amos 4.0 User's Guide," Small Waters, Chicago, 1999.

[35] M. H. Bond, "Beyond the Chinese Face: Insights from
Psychology," Oxford University Press, Hong Kong, 1991.

[36] C. S. Dweck, "Self-Theories," Psychology Press, Philadelphia, 1999.

[37] R. G. Tweed and D. R. Lehman, "Learning Considered within a Cultural Context: Confucian and Socratic Approaches," American Psychologist, Vol. 57, No. 2, 2002, pp. 89-99. http://dx.doi.org/10.1037/0003-066X.57.2.89

[38] H. W. Stevenson, S. Lee, C. Chen, M. Lummis, J. Stigler, L. Fan and F. Ge, "Mathematics Achievement of Children in China and the United States," Child Development, Vol. 61, No. 4, 1991, pp. 1953-1966.

[39] G. L. Reglin and D. R. Adams, "Why Asian American High School Students Have Higher Grade Point Averages and SAT Scores than Other High School Students," The High School Journal, Vol. 73, No. 3, 1990, pp. 143-149.

[40] F. Salili and M. K. Lai, "Learning and Motivation of Chinese Students in Hong Kong: A Longitudinal Study of Contextual Influences on Students' Achievement Orientation and Performance," Psychology in the Schools, Vol. 40, No. 1, 2003, pp. 51-70. http://dx.doi.org/10.1002/pits.10069

[41] W. O. Lee, "The Cultural Context for Chinese Learners: Conception of Learning in Confucian Tradition," In: D. A. Watkinsand and J. B. Biggs, Eds., The Chinese Learner: Cultural Psychological and Contextual influences, CERC and ACERC, Hong Kong, 1996, pp. 25-41.

[42] C. Tang and J. Biggs, "How Hong Kong Students Cope with Assessment," In: D. A. Watkins and J. B. Biggs, Eds., The Chinese Learner: Cultural Psychological and Contextual Influences, CERC and ACERC, Hong Kong, 1996, pp. 25-41.

[43] J. Biggs, "Western Misperception of the Confucian Heritage Learning Culture," In: D. A. Watkins and J. B. Biggs, Eds., The Chinese Learner: Cultural Psychological and Contextual Influences, CERC and ACERC, Hong Kong, 1996, pp. 45-67.

[44] J. L. Farh and B. S. Cheng, "A Cultural Analysis of Paternalistic Leadership in Chinese Organizations," In: J. T. Li, A. S. Tsui and E. Weldon, Eds., Management and Organizations in the Chinese Context, Macmillan, London, 2000, pp. 94-127.

[45] S. Oishi, E. F. Diener, R. E. Lucas and E. M. Suh, "Cross-Cultural Variations in Predictors of Life-Satisfaction: Perspective from Needs and Values," Personality and Social Psychology Bulletin, Vol. 25, No. 8, 1999, pp. 980-990. http://dx.doi.org/10.1177/01461672992511006

[46] T. M. Singelis, H. C. Triandis, D. P. S. Bhawuk and M. J. Gelfand, "Horizontal and Vertical Aspects of Individualism and Collectivism: A Theoretical and Measurement Refinement," Cross-Cultural Research, Vol. 29, No. 3, 1995, pp. 240-275. http://dx.doi.org/10.1177/106939719502900302 